\title{
Stretched penile length and its associations with testosterone and infertility
}

\author{
Austen D. Slade, Andrew R. Christiansen, Sorena Keihani, William O. Brant, James M. Hotaling \\ Department of Surgery, Division of Urology, University of Utah School of Medicine, Salt Lake City, UT, USA \\ Contributions: (I) Conception and design: AD Slade, JM Hotaling, WO Brant; (II) Administrative support: JM Hotaling; (III) Provision of \\ study materials or patients: JM Hotaling, WO Brant; (IV) Collection and assembly of data: AR Christiansen, AD Slade; (V) Data analysis and \\ interpretation: S Keihani, AD Slade, JM Hotaling; (VI) Manuscript writing: All authors; (VII) Final approval of manuscript: All authors. \\ Correspondence to: Austen D. Slade. Division of Urology, 30 N 1900 E, Salt Lake City, UT 84132, USA. Email: Austen.Slade@hsc.utah.edu.
}

\begin{abstract}
Background: Male infertility can be associated with secondary sexual characteristics, hypogonadism, and several findings in the examination of external genitalia. We sought to identify if stretched penile length (SPL) is associated with infertility or baseline testosterone.

Methods: We performed a retrospective review of all males age 18-59 presenting to a Men's health clinic from 2014 to 2017. SPL of patients with infertility were compared to patients with any other complaint. Patients with Peyronie's disease, prior penile surgery, prostatectomy, on testosterone replacement, clomiphene or $\beta$-hCG were excluded from our study. Baseline characteristics were compared between the two groups (infertile vs. other). Linear regression was used to assess the association between infertility and testosterone with SPL after adjusting for patient age, BMI, and race. Scatterplot was used for correlation between testosterone and SPL.
\end{abstract}

Results: Six hundred and sixty-four men were included in our study (161 infertile, 503 other). The unadjusted mean SPL in the infertile group was $12.3 \mathrm{~cm}$ compared to $13.4 \mathrm{~cm}$ in the other group $(\mathrm{P}<0.001)$. The significance remained when adjusted for age, $\mathrm{BMI}$, testosterone and race $(12.4$ vs. $13.3, \mathrm{P}<0.001)$. Mean total testosterone in the infertile group was not significantly different than the other group (414 vs. 422, $\mathrm{P}=0.68$ ). Infertile men were younger than the other group (33.2 vs. 42.1 years, $\mathrm{P}<0.001)$. BMI did not significantly differ (28.9 vs. $\left.28.9 \mathrm{~kg} / \mathrm{m}^{2}, \mathrm{P}=0.57\right)$. There was a weak positive correlation between testosterone and penile size in both the infertile group $(\mathrm{r}=0.20, \mathrm{P}=0.01)$ and the other group $(\mathrm{r}=0.24, \mathrm{P}<0.001)$.

Conclusions: Though SPL differed amongst our groups, adult testosterone levels did not. If developmental levels of testosterone exposure accounted for some of the differences in SPL between our two groups, these variations did not persist into adulthood. It remains unknown if reduced length is a result of genetic or congenital factors associated with infertility. Further investigation is needed to better understand the association of shorter SPL with male infertility.

Keywords: Male infertility, stretched penile length (SPL), anogenital distance (AGD), testosterone

Submitted Mar 18, 2020. Accepted for publication Jul 22, 2020.

doi: $10.21037 /$ tau-20-788

View this article at: http://dx.doi.org/10.21037/tau-20-788

\section{Introduction}

Male infertility is relatively common, affecting roughly 1 in 8 couples and $10 \%$ of all men; it is associated with a multitude of factors including genetics, trauma, hypogonadism, oncological diseases, and sexual dysfunction
$(1,2)$. In addition to these intrinsic factors, infertility has also been linked to environmental and lifestyle factors such as cigarette smoking, alcohol intake, drug use, obesity, psychological stress, advanced paternal age and diet (3). Previous studies have sought to identify anatomic findings that are associated with adult male fertility. The testicular 
dysgenesis theory postulates that certain genomic and environmental exposures (such as phthalates) during fetal development result in a related impact on the occurrence of hypospadias, cryptorchidism, testicular cancer and infertility (4).

One exam finding associated with male fertility is the anogenital distance (AGD), or the distance between the anus and the external genitalia. AGD is a sexual dimorphism that is approximately twice the length in males compared to female newborns (5). Fetal androgen exposure during a period known as the masculinization programming window (MPW) is critical for programming the adult dimensions of reproductive elements such as AGD and penile length (6-8). Endocrine disruptions during this period (between 8-14 weeks) can permanently alter genital development, growth, and function (7). While the potential adult size of these components is predetermined by androgen action within the MPW, their subsequent growth also depends on sufficient postnatal androgen exposure, including during puberty for penile length (6). A reduced male AGD is, therefore, potential evidence of disrupted pre- or post-natal androgen deficiency (9).

Deficient androgen exposure during the MPW results in various defects such as hypospadias, cryptorchidism, and low sperm production in addition to smaller adult testes, prostate, seminal vesicles, and penis $(6,8,10-14)$. Significantly, all of these abnormalities are paralleled by reduction in AGD, a measurement found to be stable throughout adult life $(9,15,16)$. Notably, a study by Scott et al. found that while testicular size is largely determined outside of the MPW, it still correlated highly with AGD, suggesting that some other factor is programmed by androgen activity during the MPW which affects final testis size (13). As such, correlations between AGD and various elements of reproductive development including penile length, testicular size, reproductive anomalies, sperm quality, and fertility have been demonstrated in both rodents and humans (17). Adult testicular function and infertility have been linked to a common fetal absence of androgen exposure (17). A shorter AGD has been significantly correlated with lower fertility, sperm density and total motile sperm count $(18,19)$ as well as hypogonadal testosterone levels (20).

While penile length has been associated with androgen levels in infancy and puberty $(7,14)$, it has not been correlated with adult testosterone levels (20). In addition, like AGD, penile length measurements have been suggested to be consistent throughout adult life (15). Furthermore, AGD and penile length have been shown to be highly correlated $(14,21)$. As such, it is possible that common underlying mechanisms of fetal androgen exposure are responsible for both genital development (penile length/ AGD) and fertility.

As other anatomical/genital developmental findings such as AGD have been correlated with adult fertility, we sought to identify whether adult stretched penile length (SPL) also carries this association.

The authors present the following article in accordance with the STROEB reporting checklist (available at http:// dx.doi.org/10.21037/tau-20-788).

\section{Methods}

The study was approved by The University of Utah Institutional Review Board, IRB\# 00098463. All procedures performed in this study were in accordance with the Declaration of Helsinki (as revised in 2013). Because of the retrospective nature of the research, the requirement for informed consent was waived. After obtaining institutional review board approval, we retrospectively reviewed data of all males age 18-59 presenting to a Men's health clinic from 2014 to 2017. Patients were excluded if they had a history of Peyronie's disease, prior penile surgery, prostatectomy, or if they were receiving any testosterone replacement therapy (including exogenous testosterone, clomiphene, anastrozole, or gonadotropins). SPL was measured from pubic symphysis to the tip of glans on the dorsal side using a non-flexible ruler, with penis on maximal stretch (22). SPL is an essential measurement in any male presenting with a sexual complaint, as such it was instituted as a standard exam component at our men's health clinic prior to initiation of the study period. One of three providers performed the measurements over the study period. Data on testosterone levels, based upon early morning blood draws, were collected when available.

We used $t$-test and Chi-square test to compare baseline characteristics and testosterone levels between the two groups (infertile vs. other). Patients were included in the infertile group if they were presenting to the clinic with a complaint of male infertility. The "other" group consisted of those presenting with any other urologic complaint. Pearson correlation and scatterplots were used to measure and graph the correlations between baseline testosterone and SPL in both groups. Linear regression 


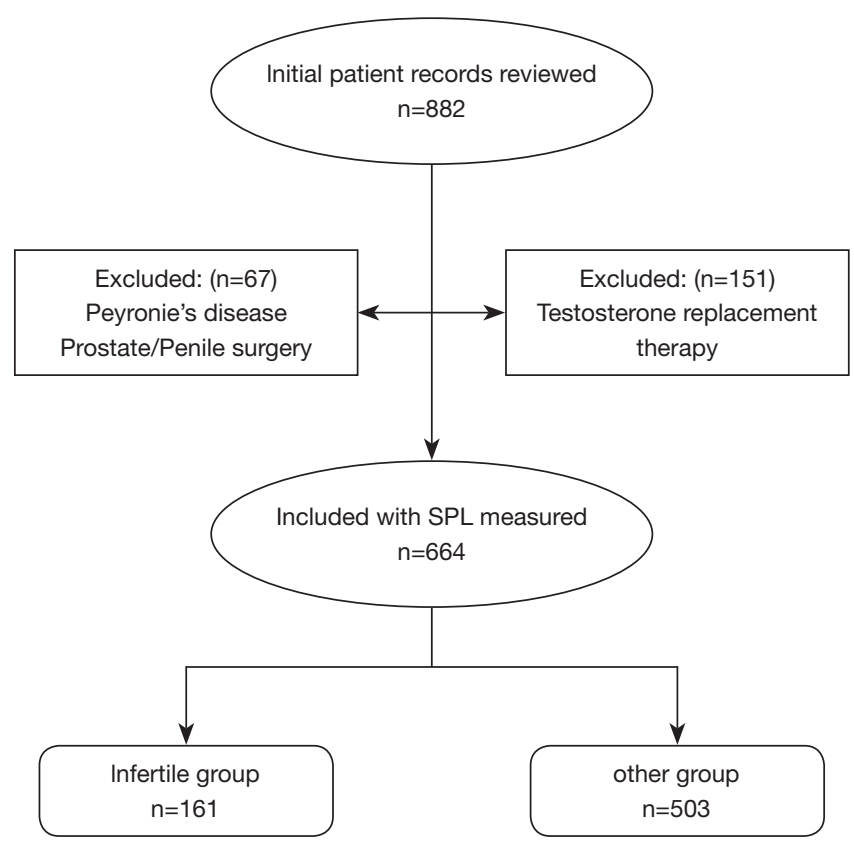

Figure 1 Patient inclusions, exclusions.

was used to assess the association between infertility and SPL after adjusting for patient age, BMI, race, and baseline testosterone.

\section{Results}

Overall, 664 patients were included in the analysis, with 161 in the infertile group and 503 who were seen for other complaints, 218 patients were excluded based on the above criteria (Figure 1). Patients who presented with infertility were, on average, younger than men in the other group (33.2 vs. 42.1 years, $\mathrm{P}<0.001)$. BMI was similar with a value for both groups and the majority of men in both groups were white/Caucasian. A total of 360 patients had testosterone levels measured (152 infertile, 208 other group); there was no significant difference in mean total testosterone between the groups (Table 1) (Normal testosterone 300-720 ng/dL).

The infertile group had an unadjusted mean SPL value of $12.3 \pm 1.9 \mathrm{~cm}$, compared to the other group with an average SPL of $13.4 \pm 2.2 \mathrm{~cm}(\mathrm{P}<0.001)$. After adjusting for age, race, $\mathrm{BMI}$, and baseline testosterone, the results were similar with SPL values of 12.4 (95\% CI: 12.0 to $12.7 \mathrm{~cm}$ ) and 13.3 (95\% CI: 13.0 to $13.6 \mathrm{~cm}$ ) for the infertile and other groups, respectively $(\mathrm{P}<0.001, \mathrm{n}=327)$.

There was a positive but weak association between baseline testosterone levels and SPL in our study population
Table 1 Patient characteristics separated by infertility vs. other group

\begin{tabular}{|c|c|c|c|}
\hline Characteristics & $\begin{array}{l}\text { Infertile } \\
(\mathrm{N}=161)\end{array}$ & $\begin{array}{c}\text { Other } \\
(\mathrm{N}=503)\end{array}$ & $P$ value \\
\hline Age, y & $33.2(6.5)$ & $42.1(11.1)$ & $<0.001$ \\
\hline $\mathrm{BMI}, \mathrm{kg} / \mathrm{m}^{2}$ & $28.9(6.7)$ & $28.9(5.3)$ & 0.95 \\
\hline Race/ethnicity (\%) ${ }^{a}$ & & & 0.05 \\
\hline White/Caucasian & 85.5 & 82.3 & \\
\hline African American & 4.1 & 3.0 & \\
\hline Hispanic/Latino & 2.1 & 8.0 & \\
\hline Other & 8.2 & 6.7 & \\
\hline Total testosterone, $\mathrm{ng} / \mathrm{dL}^{\mathrm{b}}$ & $414.2(176.8)$ & $417.2(179.3)$ & 0.87 \\
\hline Stretch penile length, $\mathrm{cm}$ & $12.3(1.9)$ & $13.4(2.2)$ & 0.001 \\
\hline
\end{tabular}

$\left(\mathrm{r}=0.22, \mathrm{r}^{2}=0.05, \mathrm{P}<0.001\right)$. In univariable linear regression, each $100 \mathrm{mg} / \mathrm{dL}$ increase in total testosterone was associated with $0.3 \mathrm{~cm}$ increase in measured SPL (slope: $0.003,95 \%$ CI: 0.001 to $0.004, \mathrm{P}<0.001)$. Similar correlations were observed in infertile and other groups (Figure 2).

\section{Discussion}

In our study we found an association between male infertility and shorter SPL. Men who presented with infertility complaints had on average $1 \mathrm{~cm}$ (95\% CI: 0.52 to $1.53 \mathrm{~cm}$ ) shorter SPL as measured during physical exam. Furthermore, there was a weak correlation between adult total testosterone levels and penile length. If variations in developmental androgen exposure are responsible for these findings, these differences did not persist into adulthood. These findings coincide with previous reports on AGD suggesting a common developmental pathway between AGD and SPL, supporting the testicular dysgenesis theory (4).

Patients who presented with infertility were an average of 9 years younger than those with other complaints. This is an expected finding as younger men likely present earlier when trying to conceive while older men present later with age-related hypogonadism, erectile dysfunction symptoms, and other complaints. The lack of variance in BMI was slightly unexpected considering that elevated BMI has been linked with male infertility (23-25). Perhaps this was offset 

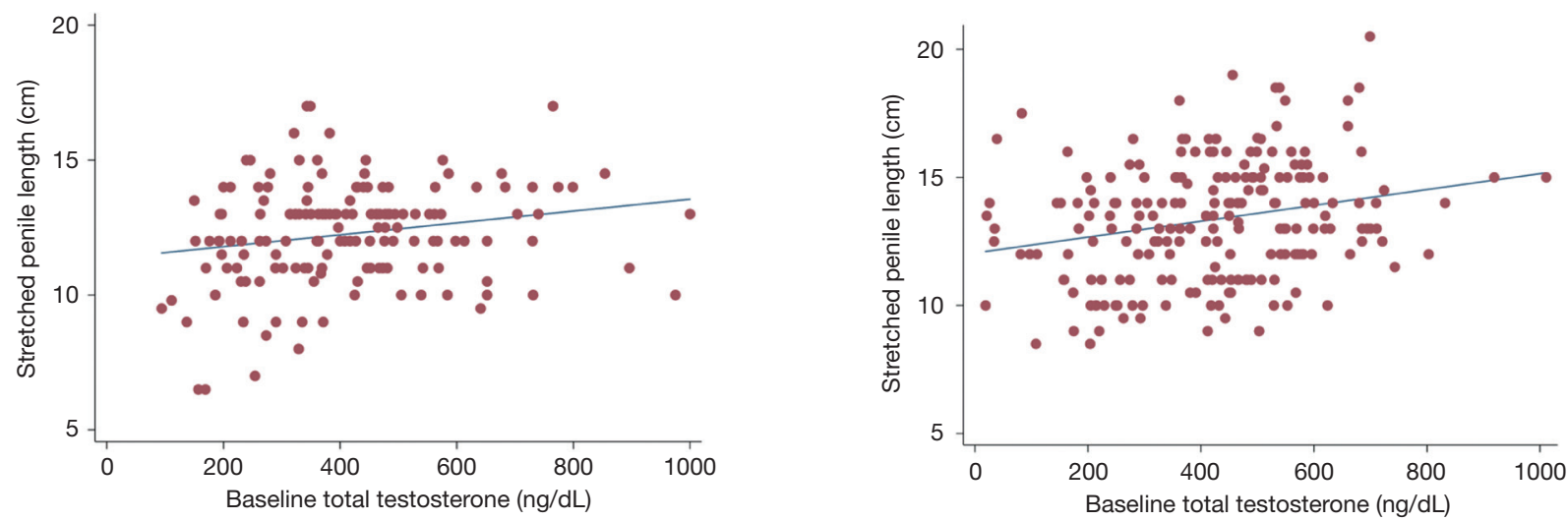

Figure 2 Association of stretched penile length (y) with baseline testosterone (x) in each group.

by patients in the other group seeking medical attention for other comorbidities of obesity including erectile dysfunction.

Previous studies have demonstrated that while prenatal androgen exposure affects the growth and eventual size of the reproductive organs, postnatal androgen exposure is still required to obtain potential growth $(6,8)$. While penile length has been shown to change prepubertally, adult penile length remains fairly constant $(7,14,15)$. It is worth noting that the SPL values we reported of $12.3 \mathrm{~cm}$ and $13.4 \mathrm{~cm}$ for the infertile and other groups respectively, are both within the normal ranges according to reported nomograms and the difference is likely without clinical significant (26-28).

Mean total testosterone levels were not different for the infertile group compared to the other group; however, there was a weak association between total testosterone levels and SPL in our patient population $(\mathrm{r}=0.22, \mathrm{P}<0.001)$. Interestingly, a study by Eisenberg et al. found increases in serum testosterone levels to be correlated with increases in AGD ( $r=0.20, P=0.03)$ and a similar association between testosterone levels and penile length $(\mathrm{r}=0.20, \mathrm{P}=0.03)(20)$. One would expect, given the shared androgen-dependent development pathways, that both AGD and penile length would be similarly affected. As mentioned, testosterone levels during development and puberty affect adult penile length (6-8). It is possible that the testosterone levels corresponding with these key penile developmental periods remain associated life long, such that men with higher developmental levels and thereby increased penile length continue to have increased testosterone levels compared to those with shorter lengths/reduced testosterone. This would suggest developmental/pubertal testosterone levels are correlated with adult levels. A study by Beking et al. found that prenatal testosterone levels did not correlate with pubertal testosterone $(\mathrm{r}=0.15, \mathrm{P}=0.440)$ though testosterone levels are highly variable, especially during puberty (29). Nomograms exist for testosterone levels of all ages, but no longitudinal studies have been performed evaluating how testosterone levels correlate over a lifetime.

While adult SPL was slightly shorter in men presenting with infertility, it remains unknown if this difference is a result of genetic or congenital factors associated with infertility, underlying hormonal differences, or a result of other confounding variables. If these study results are valid, then it provides further evidence that the pathways of AGD and penile development are linked, and that sexual dysfunction/reproductive anomalies share a root cause as proposed by the testicular dysgenesis theory. Thus far these findings should be viewed as hypothesis generating and adding to the body of medical knowledge as a whole rather than used to inform patients in a clinical setting.

\section{Caution on the interpretation of findings}

Both male infertility and penile size are sensitive topics and remarkable sources for anxiety in men (30-33). Our findings suggest a potential association between men presenting with a complaint of infertility and a shorter SPL; but it is important to understand what these findings do not mean. This is not the same as suggesting that men with shorter penile lengths have reduced fertility. Likewise, one cannot conclude that all men with infertility have reduced penile lengths. As previously mentioned, the averages of both the "infertile" and "other" groups fall within normal sizes on reported nomograms, reinforcing the idea that the shorter length found in our study in the infertile group is still within 
the normal length ranges and should not be interpreted as "short." In fact, the average difference between the two groups was only $1 \mathrm{~cm}(0.4$ inch) and is unlikely to be of any clinical significance in terms of intercourse, sexual pleasure, and fecundity.

The weak association between adult testosterone levels and penile length observed in this study, does not mean that men with higher testosterone levels have larger penises and by no means suggests that exogenous testosterone or testosterone replacement therapy will increase penile length. Importantly, it is also known that exogenous testosterone can lead to male infertility and is not recommended in men interested in having children in future (34).

\section{Limitations}

This study has a number of limitations. With lack of randomization and the retrospective nature of the study, not all confounding factors are accounted for. The "other" group does not necessarily represent "fertile" men or a random sampling of the general population as they all had some urologic complaint. Testosterone values were only available for a subset of patients and this might introduce some selection bias into our results when testosterone values are used; however, similar results were obtained when analyzing the whole patient cohort and also when testosterone values were not used in the analyses. Last, our study mostly consisted a homogenous population of young to middle-aged white/Caucasian men, thus our results might not be extrapolated to other populations with different race or ethnicity composition.

\section{Conclusions}

Our results show an association between SPL and male infertility. As SPL and AGD are both generated from similar pathways of sexual development and have each been correlated with infertility, SPL could provide similar information about testicular function and reproductive potential. Further studies should explore the possibility of an underlying link between AGD and SPL which may reveal its association with infertility and further the testicular dysgenesis theory.

\section{Acknowledgments}

Funding: None.

\section{Footnote}

Reporting Checklist: The authors have completed the STROBE reporting checklist. Available at http://dx.doi. org/10.21037/tau-20-788

Data Sharing Statement: Available at http://dx.doi. org/10.21037/tau-20-788

Conflicts of Interest: All authors have completed the ICMJE uniform disclosure form (available at http://dx.doi. org/10.21037/tau-20-788). Dr. Brant reports personal fees from Boston Scientific, outside the submitted work; Dr. Hotaling reports other from streamdx, nanonc, andro360, inherent bioscience, other from turtle health, quara, outside the submitted work. Dr. Hotaling serves as an unpaid editorial board member of Translational Andrology and Urology from Aug 2019 to Jul 2021. The other authors have no conflicts of interest to declare.

Ethical Statement: The authors are accountable for all aspects of the work in ensuring that questions related to the accuracy or integrity of any part of the work are appropriately investigated and resolved. The study was approved by The University of Utah Institutional Review Board, IRB\# 00098463. All procedures performed in this study were in accordance with the Declaration of Helsinki (as revised in 2013). Because of the retrospective nature of the research, the requirement for informed consent was waived.

Open Access Statement: This is an Open Access article distributed in accordance with the Creative Commons Attribution-NonCommercial-NoDerivs 4.0 International License (CC BY-NC-ND 4.0), which permits the noncommercial replication and distribution of the article with the strict proviso that no changes or edits are made and the original work is properly cited (including links to both the formal publication through the relevant DOI and the license). See: https://creativecommons.org/licenses/by-nc-nd/4.0/.

\section{References}

1. Gudeloglu A, Parekattil SJ. Update in the evaluation of the azoospermic male. Clinics (Sao Paulo) 2013;68 Suppl 1:27-34.

2. Punab M, Poolamets O, Paju P, et al. Causes of male infertility: a 9-year prospective monocentre study on 1737 
patients with reduced total sperm counts. Hum Reprod 2017;32:18-31.

3. Durairajanayagam D. Lifestyle causes of male infertility. Arab J Urol 2018;16:10-20.

4. Wohlfahrt-Veje C, Main KM, Skakkebaek NE. Testicular dysgenesis syndrome: foetal origin of adult reproductive problems. Clin Endocrinol (Oxf) 2009;71:459-65.

5. Salazar-Martinez E, Romano-Riquer P, Yanez-Marquez $\mathrm{E}$, et al. Anogenital distance in human male and female newborns: a descriptive, cross-sectional study. Environ Health 2004;3:8.

6. Macleod DJ, Sharpe RM, Welsh M, et al. Androgen action in the masculinization programming window and development of male reproductive organs. Int J Androl 2010;33:279-87.

7. Welsh M, MacLeod DJ, Walker M, et al. Critical androgen-sensitive periods of rat penis and clitoris development. Int J Androl 2010;33:e144-52.

8. Welsh M, Saunders PT, Fisken M, et al. Identification in rats of a programming window for reproductive tract masculinization, disruption of which leads to hypospadias and cryptorchidism. J Clin Invest 2008;118:1479-90.

9. Schwartz CL, Christiansen S, Vinggaard AM, et al. Anogenital distance as a toxicological or clinical marker for fetal androgen action and risk for reproductive disorders. Arch Toxicol 2019;93:253-72.

10. Drake AJ, van den Driesche S, Scott HM, et al. Glucocorticoids amplify dibutyl phthalateinduced disruption of testosterone production and male reproductive development. Endocrinology 2009; 150:5055-64.

11. Foster PM, Mylchreest E, Gaido KW, et al. Effects of phthalate esters on the developing reproductive tract of male rats. Hum Reprod Update 2001;7:231-5.

12. Hsieh MH, Breyer BN, Eisenberg ML, et al. Associations among hypospadias, cryptorchidism, anogenital distance, and endocrine disruption. Curr Urol Rep 2008;9:137-42.

13. Scott HM, Hutchison GR, Jobling MS, et al. Relationship between androgen action in the "male programming window," fetal sertoli cell number, and adult testis size in the rat. Endocrinology 2008;149:5280-7.

14. van den Driesche S, Scott HM, MacLeod DJ, et al. Relative importance of prenatal and postnatal androgen action in determining growth of the penis and anogenital distance in the rat before, during and after puberty. Int J Androl 2011;34:e578-86.

15. Eisenberg ML, Hsieh TC, Lipshultz LI. The relationship between anogenital distance and age. Andrology
2013;1:90-3.

16. Jain VG, Goyal V, Chowdhary V, et al. Anogenital distance is determined during early gestation in humans. Hum Reprod 2018;33:1619-27.

17. Dean A, Sharpe RM. Clinical review: Anogenital distance or digit length ratio as measures of fetal androgen exposure: relationship to male reproductive development and its disorders. J Clin Endocrinol Metab 2013;98:2230-8.

18. Eisenberg ML, Hsieh MH, Walters RC, et al. The relationship between anogenital distance, fatherhood, and fertility in adult men. PLoS One 2011;6:e18973.

19. Eisenberg ML, Shy M, Walters RC, et al. The relationship between anogenital distance and azoospermia in adult men. Int J Androl 2012;35:726-30.

20. Eisenberg ML, Jensen TK, Walters RC, et al. The relationship between anogenital distance and reproductive hormone levels in adult men. J Urol 2012;187:594-8.

21. Thankamony A, Ong KK, Dunger DB, et al. Anogenital distance from birth to 2 years: a population study. Environ Health Perspect 2009;117:1786-90.

22. Davoudzadeh EP, Davoudzadeh NP, Margolin E, et al. Penile Length: Measurement Technique and Applications. Sex Med Rev 2018;6:261-71.

23. Katib A. Mechanisms linking obesity to male infertility. Cent European J Urol 2015;68:79-85.

24. Nguyen RH, Wilcox AJ, Skjaerven R, et al. Men's body mass index and infertility. Hum Reprod 2007;22:2488-93.

25. Sermondade N, Faure C, Fezeu L, et al. BMI in relation to sperm count: an updated systematic review and collaborative meta-analysis. Hum Reprod Update 2013;19:221-31.

26. Veale D, Miles S, Bramley S, et al. Am I normal? A systematic review and construction of nomograms for flaccid and erect penis length and circumference in up to 15,521 men. BJU Int 2015;115:978-86.

27. Hussein NS, Abid AF, Alnuaimi AS. Reference range of flaccid and stretched penile lengths of adult males in Baghdad: A cross-sectional study. Arab J Urol 2017;15:68-73.

28. Khan S, Somani B, Lam W, et al. Establishing a reference range for penile length in Caucasian British men: a prospective study of 609 men. BJU Int 2012;109:740-4.

29. Beking T, Geuze RH, van Faassen M, et al. Prenatal and pubertal testosterone affect brain lateralization. Psychoneuroendocrinology 2018;88:78-91.

30. Petok WD. Infertility counseling (or the lack thereof) of the forgotten male partner. Fertil Steril 2015;104:260-6. 
31. Veale D, Eshkevari E, Read J, et al. Beliefs about penis size: validation of a scale for men ashamed about their penis size. J Sex Med 2014;11:84-92.

32. Veale D, Miles S, Read J, et al. Relationship between selfdiscrepancy and worries about penis size in men with body dysmorphic disorder. Body Image 2016;17:48-56.

Cite this article as: Slade $\mathrm{AD}$, Christiansen $\mathrm{AR}$, Keihani S, Brant WO, Hotaling JM. Stretched penile length and its associations with testosterone and infertility. Transl Androl Urol 2021;10(1):49-55. doi: 10.21037/tau-20-788
33. Wylie KR, Eardley I. Penile size and the 'small penis syndrome'. BJU Int 2007;99:1449-55.

34. Crosnoe LE, Grober E, Ohl D, et al. Exogenous testosterone: a preventable cause of male infertility. Transl Androl Urol 2013;2:106-13. 